\title{
6.5 Features of studying the discipline "basis of ecology" by students of biotechnology
}

The life of the average person today is filled with comfort. He travels long distances in a private car, plane or train, his diet consists of a variety of dishes, and his health is monitored by a whole army of doctors who make up a unified healthcare system. But this is only at first glance. In fact, each of us is constantly faced with serious risks that we may not even be aware of. We are talking about global environmental problems.

The ecological problems of the planet Earth are ecological crisis situations that are relevant for the entire planet, their solution is only possible with the participation of all mankind. I would like to immediately note that any environmental problems of the Earth are closely related to each other. We are talking about global problems of mankind, where the emergence of some leads to the emergence and aggravation of others.

There are so many environmental problems that cause excitement and disturb the soul, it is rather difficult to address everything. I want to focus and concentrate on seven, as well as motivate and inspire students to determine the degree and level of pollution, using not only highly sensitive instruments and analyzers, but also organoleptic methods that help find means and methods for solving environmental problems.

Global warming, the consequences of which are far from rosy (e.g., rising sea levels, declining agricultural production, fresh water shortages, greenhouse gases and other responses) have been worrying environmentalists and ordinary people around the world for several decades. There are some options that can help solve this problem, such as reducing carbon dioxide emissions and switching to carbon-free fuels, as well as developing a more economical fuel strategy, but these are not enough.

Overpopulation of the planet can lead to shortages of food, water and energy, as well as an increase in the number of diseases. Recently, new dangerous diseases caused by viruses and bacteria have appeared almost every year, for instance, COVID-19, the 
main and most global problem of our day. Endless epidemics, chronic diseases, social tensions and territorial conflicts over water sources torment people, forcing them to leave their homeland and go in search of a better life.

One environmental problem that leads to an increase in the flow of ultraviolet radiation to the Earth's surface is the depletion of the ozone layer. Steadily reducing the volume of ozone in the atmosphere, which serves to protect life on the planet from the harmful effects of ultraviolet rays. Increasingly, doctors are faced with serious sunrelated illnesses. The first ozone holes were discovered over the northern regions [Israel, 1984; Ecology of the city, 2000]. This fact is explained by artificial and natural reasons: flights of spaceships, satellites and jet planes, emissions of freons used in refrigeration units and air conditioners, shortage of ultraviolet radiation in winter. The percentage of ozone layer depletion over countries with a temperate climate has decreased by an average of $10 \%$, which negatively affects human health, there are problems with skin, eyesight and a number of others. Among other things, as a result of excessive ultraviolet radiation, significant damage is caused to agriculture [Environmental Protection, 1991].

The decline in biological diversity is another of the striking examples of intensive human activity; many species of animals and plants have disappeared from the face of the Earth. Unfortunately, this trend continues, and its main problems are considered to be the loss of habitat, overexploitation of biological resources, competition with biological species brought from other territories, and large-scale environmental pollution. There is a close correlation between all links of the biogeocenosis. In case of violation of one of the links of the biogeocenosis, the entire system is upset. The technogenic society has made amendments to the withering away of old and the emergence of new forms of living organisms. The natural duration of development of one species before human intervention is from one and a half to 2 million years. In this day and age, hundreds of thousands of species disappear annually, which results in a decrease in the area of population of animals, and this is a real ecological catastrophe.

It is sad to realize that about a third of the world's population suffers from a shortage of fresh water and at this time no active measures are being taken to preserve 
natural sources. Most cities around the world do not properly treat wastewater and this is one of the factors contributing to the pollution of rivers and lakes and other bodies of water. For several centuries, mankind has been using in industry toxic chemicals, heavy metals, chemical protection of cultures of biogeocenoses (pesticides). The laws of ecology testify and confirm that it is unrealistically difficult, or practically impossible, to restore and clean up an ecosystem subject to severe degradation due to pollution. Minimizing the release of harmful compounds, installing treatment facilities, monitoring and control will help assess the real situation and help protect the environment [Kobyakov et al., 2020]. For several years now, the scientific ecological community has been looking for technologies to solve such a problem as the pollution of the world's oceans with plastic waste. At the moment, five huge garbage islands have been discovered that drift in the waters of the Pacific, Atlantic and Indian oceans and pose huge risks to all their inhabitants. Some animals and fish mistake the microplastics for phytoplankton and consume them. Chicks of seabirds are attracted by larger plastic pieces of bright colors, young birds swallow them, condemning themselves to painful death. At the moment, no combination of technical and costeffective means to solve this situation has been developed. However, new concepts and ideas are constantly being researched by economists and scientists.

Deforestation is taking place at alarming speeds around the world. It is with good reason that forests are called the lungs of the planet, processing carbon dioxide, increasing the concentration of oxygen, which is necessary for the breathing of all life on the planet. In addition, deforestation leads to risks such as soil desertification and loss of biodiversity. It is extremely difficult to stop these processes, but it is necessary using integrated approaches and solving economic, social, and political problems.

Residents of megalopolises are especially concerned about the problem of air pollution. Huge volumes of exhaust gases, and industrial emissions envelop cities in a thick layer of smog, in which it sometimes becomes difficult to breathe. Hence, numerous health problems in adults and children. It is possible to clean the air from impurities through the reduction of road transport, the use of multistage purification 
systems at industrial enterprises, as well as through the widespread use of energysaving technologies.

Today, when the entire planet is under the influence of anthropogenic factors, significant changes are taking place in both living and inanimate nature. The improvement and harmonization of human relations with the environment is of great importance. We receive from nature everything we need for life, energy, food, various materials, emotional and aesthetic pleasure. Therefore, today, as never before, it is necessary not only to have a clear strategy for environmental protection and strengthen control over nature management, but also a well thought out system of environmental education and training. In modern conditions the problem of nature's relation to society is coming to the center of attention of the world community. The chaotic and incompetent use of natural resources has led to the emergence of a system of conflicting situations [Poleva, 2020]. Of course, most of them go deep into the history of mankind. However, the development of various industries and a lack of research and knowledge about the laws of nature have exacerbated the conflicting situation and given it a global character.

Achievements of mankind in various fields of science and technology will not be able to improve human life if they contradict the laws of nature. It is necessary to pay attention to the use of natural resources, taking into account and knowledge of the basic laws of ecology, and paying attention to the degree of anthropogenic pressure on ecosystems. Safe ecological development is one of the main tasks of humanity. New knowledge, forms of behavior, development and improvement of waste-free resourcesaving technologies will help to solve these problems. Due to the fact that ecology, under conditions of intensive practical use, has become an integral science, which has a direct connection with the natural sciences as well as with special disciplines, in different educational institutions its teaching is based on the specialization of students. Unfortunately, complementary practical work is not always available, although it is no secret that gaining practical experience increases understanding of classroom and laboratory knowledge. In my opinion, practical work helps not only to master the theoretical part of the subject and make sure that the laws of ecology really work, but 
also makes students look around, be aware of, and recognize signs, signals and "beacons" of nature, indicating the scale and seriousness of environmental pollution.

The goal of education of students of ecology requires them to understand the above-mentioned problems facing the environment. One area of concentration here at the Ukraine Agricultural University aimed at addressing some of the foreseeable food shortage problems, while keeping in focus the minimization of environmental damage, is the study of fisheries. Ensuring food security at the expense of resource, naturalclimatic and innovative potential is an important task of the current stage of development of fisheries. Currently, fisheries and aquaculture are receiving increasing attention, since these areas are important in the socio-economic development of various areas of the world and national economies, as well as sources of income, including from foreign exchange earnings, and to provide domestic markets with safe and highquality food [Bogeruk, 2011]. Fisheries are also a source of livelihood for millions of people around the world, and employment in the fisheries and aquaculture sectors has increased significantly over the past three decades, growing at an average annual rate of $3.6 \%$ since 1980. [FAO, 2014].

With the growth of the world's population, the demand for products from raw materials of water origin is increasing. However, the growth in catches of fishing is slowing down, as most of the important fishing areas have reached the limits of exploitation of their resource potential, and for many sites there is a critical state of stock in oceanic and inland waters. The quantity of fish caught has remained relatively stable since the mid-1980's within the range of 85-95 million tons. However, the efficiency of world fishing is steadily declining, and its average annual growth remains at the level of no more than 1.1 million tons [Zolotova, 2000].

In 2007, the US Food and Drug Administration published data that by 2030, if food consumption is maintained at today's level, the world's population will need an additional 40 million tons of fish per year. Natural reserves of aquatic biological resources will not be able to provide such a level of consumption. Moreover, the report of the International Council for the Exploitation of Marine Resources of the European Union states that if the current methods and volumes of fishing are not changed, then 
by 2050 the global fishing industry will cease to exist due to the lack of raw materials. Perhaps this may seem an overly pessimistic forecast, but it is grounded in real statistical evidence. As a result, the only source of increase in the volume of fish products and the most important component of the agro-industrial and fishery sectors of the economy is aquaculture, which provides the primary potential for increase in world fish production.

Aquaculture is human-controlled breeding and rearing of aquatic organisms in order to obtain valuable food, feed and technical products [Bogeruk, 2011]. At the moment, it is no less important for fisheries than for agriculture similar to the transition from hunting and gathering to agriculture and animal husbandry [Zolotova, 2000]. Modern artificial farming of fish and other aquatic animals and plants is based on the experience accumulated by mankind over many centuries and even millennia. It is generally accepted that the cultivation of aquatic organisms originated in China 3.5-4 thousand years ago [FAO, 2014]. However, despite the centuries-old traditions of fish farming in some countries, globally aquaculture is a young food industry that has experienced a period of rapid growth over the past 50 years [FAO, 2016]. The importance of aquaculture production in the world is constantly increasing, which is reflected in the materials of numerous meetings and forums of various international organizations, including the United Nations (UN) and the UN Food and Agriculture Organization (UN FAO) [Bogeruk, 2011].

Aquaculture is an integrated multifunctional sector of the fishery complex, which is currently expanding, becoming more diversified, dynamic, technically and technologically advanced. The global nature of the development of aquaculture inevitably entails an increase in cultivated areas and the number of farms of various types, a higher density of growing aquaculture objects, and widespread use of forage resources. The intensification and industrialization of aquaculture production leads to an increase in the volume of fish production, the restoration of the number of endangered or too-actively fished populations of aquatic biological resources, and provides positive socio-economic results. Governance and policy in global and national aquaculture are aimed at ensuring integrated multifunctional economic, social, 
environmental, legal and organizational development [Kozlov et al., 2004; Bogeruk, Lukanova, 2010]. The role and importance of aquaculture in the socio-economic development of different countries and regions of the world can vary and are determined by a diverse complex of reasons, among which an important place belongs to specially developed strategic documents that provide guidance for the production and marketing of aquaculture products [Bogeruk, 2011].

Saturation of the domestic fisheries market requires a significant increase in the volume of aquaculture production, which in turn is associated with a number of considerations, such as the provision of specialized feed, the occurrence of diseases of farmed objects, environmental complications, personnel training, and insufficient level of management. It is important for countries to develop domestic products and avoid importing products from other countries. Such work, first of all, is associated with the promotion of traditional products for any given country, which is possible only if it is safe and of high quality, environmentally friendly, and cost competitive. Developed strategic documents in the field of aquaculture to ensure these conditions should be built on an innovative basis using scientific and technological advances and modern management techniques [Bogeruk, 2011].

The curriculum of future specialists in aquatic biological resources and aquaculture should include the basic apparatus of concepts that help to strengthen ecological orientation and provide a competent approach in terms of environmental safety. The objectives of mastering the discipline "Fundamentals of Ecology" are: teaching the basics of research and development of modern biotechnological methods of the environment, and the formation of students' skills in applying biotechnology methods to protect the environment. The objectives of the discipline "Fundamentals of Ecology" for students specializing in aquatic biological resources and aquaculture are: the formation of knowledge about natural biological processes occurring in all natural ecosystems and the principles of their use, teaching the skills of laboratory work with biological objects, bringing the basic principles of organizing biological processes based on modern advances in science, and teaching theoretical and methodological foundations and practical skills in the use of modern methods of disposal of all types 
of pollution associated with human economic activity [Grinzhevsky, 2006; Kovalenko, 2014].

Teaching the discipline "Fundamentals of Ecology" for students of the specialty "Aquatic Bioresources and Aquaculture", in my opinion, should consist of three main aspects - methodological, didactic and applied. The main focus of environmental education in higher educational institutions should be the transition from informative demonstrative to interactive forms of education, which are achieved in lectures, laboratory, practical, and individual lessons. Production situations, modeling and forecasting methods, research assignments, seminars and discussions will help to unleash the creative potential of future specialists in the field of aquatic biological resources. In addition, the knowledge and skills gained in the multifaceted study of the discipline will help future specialists to act according to the situation, to look for nonstandard and non-traditional approaches to solving certain problems.

In order to solve the global issues of the millennium, the deterioration of the quality of drinking water, pollution of water bodies and air with products of various origins, a decrease in biodiversity, climate change, and a number of other environmental problems, the goal of the "Fundamentals of Ecology" discipline for future biotechnologists is to strengthen environmental education, science and culture. As you can see, the risks faced by our world are many. However, there is only one underlying reason for them, the consumer's attitude as a person toward the planet, its resources, other living beings inhabiting it and, moreover, to each other. None of the above problems can be solved in isolation. They can be solved only in a complex manner, provided that the vector of our consciousness changes towards the perception of the Earth as our common home, as a single living organism, of which we are all cells. 